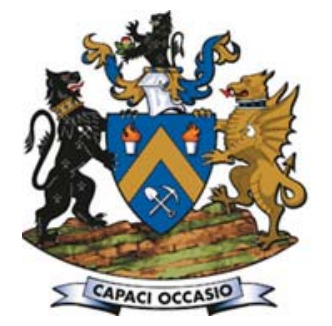

\title{
Factors and challenges affecting coal recovery by opencast pillar mining in the Witbank coalfield
}

\author{
by P.L. Ngwenyama*, W.W. de Graaf*, and E.P. Preis*
}

\section{Synopsis}

The depletion of coal reserves in the Witbank coalfield in Mpumalanga Province has resulted in mining companies exploring the possibilities of extracting coal pillars. These are pillars that were left behind for hangingwall support during underground bord-and-pillar operations. Recent studies of in situ pillar mining have found the extraction of the pillars to be feasible during opencast mining due to the high extraction rates of coal, relatively low stripping ratio, safety of the operation, and general environmental requirements. The geological model of an opencast pillar mining operation within the Witbank coalfield has indicated that some $30 \%$ of the coal in the no. 2 seam remains in pillars. The no. 4 and no. 1 seams are yet to be mined. Opencast pillar mining requires maximizing coal recovery in order to be competitive in the market, since a portion of the resource has already been extracted. Exposure and recovery of the coal are crucial in reducing coal losses and dilution due to the coal pillars and voids, and challenges experienced during the mining of pillars from surface. The reconciliation process evaluated the overall flow processes, from in situ coal to the mined-out coal. The similarities between opencast pillar mining and conventional opencast mining were studied in terms of the mining sequence, pit layout, and operations. A correlation between the SAMREC Resource and Reserve definitions was conducted through an investigation of coal losses and contamination during mining. The various types of coal losses affecting production volumes were investigated. The dilution of coal was found to be higher in the no. 2 seam due to blasted material filling the voids in the bords. The presence of bord voids is one of the factors that increases the risk of spontaneous combustion. This in turn affects the productivity of the operation, with buffer blasting management and cladding techniques used to reduce the risk of spontaneous combustion.

\section{Keywords}

coal recovery, pillar extraction, opencast mining, coal losses.

\section{Introduction}

The Witbank coalfield in Mpumalanga Province holds one of the largest coal resources in South Africa and the rest of the world. Both export and domestic coal are produced from various mines in the coalfield. The study was based on one of the mines, which produces both export coal and domestic coal which is supplied to a nearby Eskom power station. The mine is currently mining pillars from a previous underground bord-andpillar operation as well as a virgin coal seam. The pillars are extracted using a surface mining method referred to as opencast pillar mining, with an aim of maximizing coal recovery from the pillars. The selection and design process of the opencast pillar mining method was also influenced by the coal production rates and demand from the power station. Three seams are being mined; the no. 4 lower seam (S4L), no. 2 seam (S2), and the no. 1 seam (S1). The S4L and S1 are virgin coal seams while the $\mathrm{S} 2$ resources consist of pillar coal remaining from a previous bord-and-pillar operation that reached its end of life in the 1980s. The underground mine was operated using the conventional drill-andblast, bord-and-pillar mining method. The pillars were left intact when the underground operation was shut down.

In 1995, a project to extract the remaining pillars was started as part of an initiative to extend the life of the mine. The extraction of the pillars was found to be economically feasible due to the good quality coal remaining in the pillars (Table I). Overburden removal began in 2000 using a truck-and-shovel fleet. This was an initial and experimental approach with the intention of exploring the risks associated with the pillar mining method, which was uncommon at that time. The truckand-shovel operation included cleaning around the pillars, which resulted in extensive coal losses. Due to the size of the equipment it was possible to dig the pillars without the need for blasting. It was then decided to implement a dragline operation together with the truckand-shovel fleet to overcome challenges with stability and spontaneous combustion on the midburden bench above the mined-out pillars. The first dragline was introduced in 2004. The use of the dragline was not part of the original design, and it was introduced only after it was identified as a lower risk operation compared to the truck-and-shovel fleet on the midburden.

\footnotetext{
* Department of Mining Engineering, University of Pretoria, South Africa.

(c) The Southern African Institute of Mining and Metallurgy, 2017. ISSN 2225-6253. This paper was first presented at the New technology and innovation in the Minerals Industry Colloquium', 9-10 June 2016, Emperors Palace, Johannesburg, South Africa.
} 


\section{Factors and challenges affecting coal recovery by opencast pillar mining in Witbank}

Table I

Average coal properties for the three mined seams

\begin{tabular}{|c|c|c|c|}
\hline Seam & Thickness (m) & Calorific value (MJ/kg) & Ash content (\%) \\
\hline $\begin{array}{l}\text { No. } 4 \text { seam } \\
\text { No. } 2 \text { seam (S2RPB) } \\
\text { No. } 1 \text { seam }\end{array}$ & $\begin{array}{l}2.3 \\
4.0 \\
2.3\end{array}$ & $\begin{array}{l}24.6 \\
24.9 \\
23.9\end{array}$ & $\begin{array}{l}22.7 \\
22.1 \\
25.9\end{array}$ \\
\hline
\end{tabular}

The S2RPB seam comprises three horizons: the S2R (no. 2 seam roof coal); S2P (no. 2 seam pillar coal); and S2B (no. 2 seam bottom coal). The $\mathrm{S} 1$ seam is separated from the S2RPB seam by parting material that varies between $0.1 \mathrm{~m}$ and $28.0 \mathrm{~m}$ in thickness across the Witbank coalfield, and is approximately $7.0 \mathrm{~m}$ thick on average. The $\mathrm{S} 1$ seam is extracted together with the S2RPB seam where the parting is very thin. The extraction of the pillars was found to be feasible through the use of opencast mining methods due to the low stripping ratio, high recovery and extraction rate, and environmental and safety factors. This seam split was a function of the different products, with the pillar coal destined to produce export-type coal products and the roof and floor coal used in the adjacent power station after beneficiation in a separate plant. The pillars of the S2 seam in the ground are depicted in Figure 1.

The S2RPB seam, simply referred to as the S2RP seam, was of major concern due to the potentially disturbed and deteriorated conditions of the pillars since the underground workings stopped some years ago. The geological polygon of the mine indicated that some $30 \%$ of the coal remains in the pillars and as remnant coal in the roof and floor of the previous underground workings. The amount of coal remaining in the pillars was determined from the areal extraction ratio and the average mining height (seam thickness). The average mining height was taken into account due to the inconsistencies in the seam thickness. In some areas, roof and floor coal had been recovered, but this was not always indicated on the survey plans. This discovery was based on recent exploration activities preparatory to the exploitation of the pillars. Investigations were conducted mainly to establish wash plant parameters in the initial design, while the volumes of the floor and roof remnants were calculated from survey plans of the previous operation. As physical access to the workings was not possible, all information had to be obtained from survey plans, which are not always accurate, and from earlier exploration boreholes, which were not subjected to wash analysis as is done currently. The pillars and remnant coal of the S2RP seam situation are illustrated in Figure 2.

When bord-and-pillar mines reach their end of life, coal pillars are inevitably left unmined. A forecast can be made as to the feasibility of effective, efficient, and responsible utilization of the reserves remaining in previously mined-out areas (Schalekamp, 2006). The underground conditions may have changed with time, and this makes it difficult to predict the underground conditions. Jeffrey (2002) investigated the geotechnical factors that influence secondary extraction in previously mined-out coal seams. The current underground conditions of opencast pillar mining operations are expected to be as illustrated in Figure 2, but cannot be defined accurately, because underground access was sealed off; however, the old survey plans have proven to be accurate enough for volume calculations. Understanding the coal volumes is crucial for maximizing coal recovery. This was done by evaluating the variations between theoretical and actual mined volumes.

The global coal industry loses about US $\$ 480$ million (R5.5 billion) annually in revenue (Thompson, 2005) due to coal losses in the mining process and contamination. The coal price in 2005 was about US\$45 per ton (InfoMine, 2015), which means that approximately $10.7 \mathrm{Mt}$ of coal was lost. Coal losses are therefore a major concern for pillar mining operations, since only $30 \%$ of the original coal reserves remain underground as old pillars in the no. 2 seam. Coal losses affect operational revenue and are included in the current operating costs. It is thus critical for operations to strive for maximum recovery of reserves (Johnston and Kelleher, 2005). The extraction of pillars through normal opencast mining methods has been found to be a fundamental factor leading to high dilution. The high dilution is due to the large bord voids between the pillars, and this is a major concern in terms of the operating costs, especially the processing plant operating costs. The main aim of collapsing the bords, which incurs high dilution, was to maximize coal recovery, while the washing plant would remove waste from the ROM coal. The mining of pillars from surface causes air to penetrate the old workings, resulting in spontaneous combustion, which is one of the big challenges in opencast pillar mining operations. Spontaneous combustion causes in situ coal to burn, and this decreases coal quality and quantity, and leads to the emission of noxious gases. The continuous burning of coal in the pit also produces large

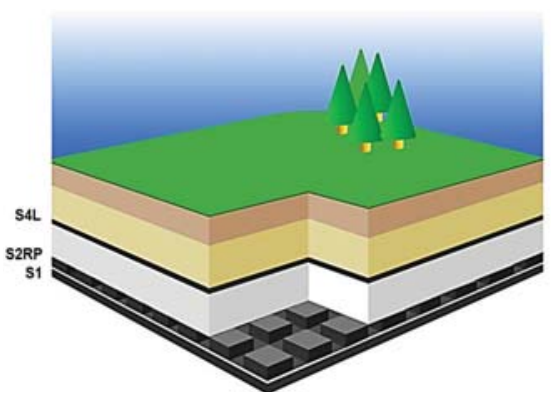

Figure 1-Pillars remaining after previous bord-and-pillar operation

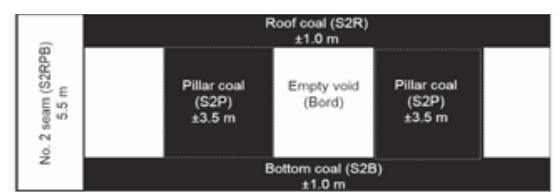

Figure 2-Sectional view of the S2RP seam composition 


\section{Factors and challenges affecting coal recovery by opencast pillar mining in Witbank}

volumes of dust, dark smoke, and harmful gases during waste removal, which has a deleterious impact on productivity and the environment. A large portion of the dust is created during dumping on the low-wall side.

\section{Opencast pillar mining method}

Opencast pillar mining follows a similar layout and stripping sequence to conventional opencast mining. The similarities of the two methods are mainly due to the dragline operation. Equipment selection was influenced by the risks of opencast pillar mining, particularly spontaneous combustion. The dragline is allowed to mine only one bench at a time before moving to the next strip. Exposure of multi-seams at a double bench pass is risky in pillar mining. Hence the dragline on a multi-pass single bench method is preferred in pillar mining operations, while the dragline on a multi-pass double bench is applicable in conventional opencast operations. There are minor differences in the layout of the two methods; for example, opencast pillar mining makes use of a $30.0 \mathrm{~m}$ wide blasted buffer to prevent spontaneous combustion and sinkhole formation. Buffer blasting was, and still is, the most effective technique for containing spontaneous combustion. It may not prevent spontaneous combustion completely, but will significantly retard the process.

The buffer is indicated by the dashed blue outline in Figure 3. This is carried over to the next strip of extraction. Cladding is provided by cast-blasting the overburden to cover the edge of the highwall, thus filling the bords and creating the buffer. The mining sequence is similar to the stripping sequence in conventional opencast:

> Removal and stockpiling of topsoil material

> Drilling, charging, and blasting of overburden

> Push over and pre-stripping of overburden using truck and shovel operation

> Stripping of blasted overburden with dragline

- Extraction of S4L coal seam

> Drilling, charging, and blasting of mid-burden

> Stripping of midburden with dragline

> Free digging of S2RP seam coal and blasting of hard pillars

Drilling, charging, and blasting of S1 parting

> Extraction of S1 coal seam.

Buffer management and cladding techniques were implemented to minimize or prevent the continuous burning of coal in the ground. The old pillars are only in the S2RP seam, and are approximately $7.0 \times 7.0 \mathrm{~m}$, with a bord width of $6.1 \mathrm{~m}$ between the pillars. There are larger pillars in certain blocks, referred to as barrier pillars during the bord-andpillar operations. The orientation of the pillars was designed

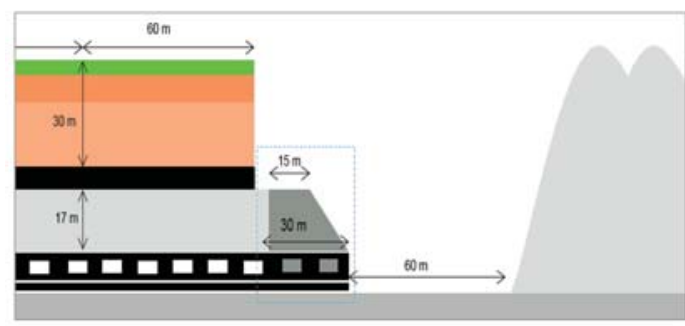

Figure 3-Opencast pillar mining method layout to cut across the strips at an angle, and not parallel to the strips. Thompson (2005) mentioned that this was aimed at increasing the stability of the highwall side or edge. When the pillars are at an angle, the highwall edge will always be supported by pillars, thus preventing the highwall from hanging unsupported above the bords. This also prevented large open spaces being left between two pillars. The risk of flooding from water accumulation in the panels also had an influence on the initial orientation direction of the pillars. A plan view of the pillar orientations relative to strip direction is shown in Figure 4.

\section{Resource and Reserve utilization}

Reserve models are built and scheduled from a Resource model to determine the profitability of a mine by accounting for realistic factors that may affect the operation, such as coal losses and dilution. The Resource and Reserve models are based on theoretical calculations. The theoretical calculations are put in place to accommodate wide ranges in coal qualities. These differences are corrected or modified by survey volumes that show the real volumes. Losses, dilution, and contamination are critical parameters as they play a major role in the Resource to Reserve conversion process. These factors act as intermediary factors between Resources and Reserves, as well as in moving from mineable in situ and run-of-mine to saleable Reserves.

There are three main parameters that should be considered, according to the SAMREC Code:

> Mineable in situ Coal Reserve-The tonnages and quality of the coal at a particular moisture content contained in the in situ coal seam. This portion of the Mineable Reserve is used in conceptual and detailed mine planning. The mining method and planned losses are determined at this stage

$>$ Run of Mine Reserve (ROM) - Run of Mine Reserves are based on the Mineable in situ Reserves. This is the actual amount of coal expected to be extracted and delivered to the plant, usually over a particular time period. The Run of Mine Reserves are the tonnages and coal qualities remaining once the following factors have been accounted for:

- Coal losses during mining

- Dilution and contamination

- Moisture content of coal

- Others, such as geological losses

- Saleable Coal Reserve-The actual tonnages with a particular quality that will be available for market sales. This is calculated from the ROM tonnages after washing and beneficiation to the required product quality.

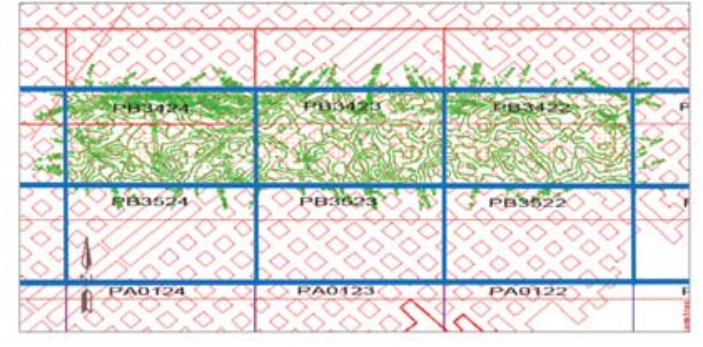

Figure 4-Plan view of intact pillars in the ground 


\section{Factors and challenges affecting coal recovery by opencast pillar mining in Witbank}

According to the SAMREC Code, the estimation of Reserves and Resources in previously mined workings is very complex compared to virgin coal grounds. This is due to the necessity of considering and accounting for the previously extracted voids. The currently unknown conditions of the standing pillars underground makes it difficult to build the Reserve model by predicting the applied losses. Schalekamp (2006) explained that a proper and accurate reconciliation between planned and actual mineable tonnages requires an extensive survey. However, he noted that it is difficult to conduct physical surveys due to the risks of working directly above blasted and collapsed old workings. The presence of spontaneous heating also makes the risk of surveying more complex in those areas, and semi-collapsed and uncollapsed voids pose further risks. The major challenge is the estimation of the top of coal losses, while highwall and edge losses are easier to estimate.

A review of the Resource (geological) versus Reserve model of the mine was conducted to perform a coal mass balance (Figures 5-7). This was done to ascertain whether coal losses and dilution are correctly utilized, especially on the S2RP seam. The no. 2 seam contains voids that become filled with waste from midburden blasting. The dilution was then calculated, theoretically and from plant data, to be approximately $20 \%$. This is a theoretically calculated value that could not be physically measured. The data was based on portions of strips that are currently being mined, and those that are scheduled to be mined in the next two to three years. The Reserve was built from the geological model data, which was obtained from the GEMCOM Minex Software used to create the Resource models, by applying some assumptions as modifying factors for the conversion process (Table II). The modifying factors were applied for the three seams being mined.

Figure 6 and Figure 7 indicate that there is no constant correlation or relationship between the Resources and Reserves of the S2RP and S1 seams as compared to the S4L (Figure 5). Figure 6 shows the Resource of the remaining pillar and remnant coal versus the Reserve, taking into account the expected dilution from collapsing the bords. The Reserve is greater than the Resource because the dilution will be higher than the potential losses. The dilution factor may be reduced by the presence of large barrier pillars, while the losses remain constant. This causes the interchanging of the Resource and Reserve tonnages on the S2RP seam. The interchange between the Reserve and Resource tonnages in Figure 7 is influenced by the fact that the $\mathrm{S} 1$ seam is sometimes mined together with the parting. The parting is blasted together with the S1 seam where its thickness is less than $0.5 \mathrm{~m}$, and separately where the thickness is greater than $0.5 \mathrm{~m}$. The relationship between the Reserve and
Resource is depends mainly on the dilution and coal loss factors:

Reserve $=$ Resource + Dilution - Losses \pm Other (Minor)

There are other factors considered in the Reserve model, such as inherent moisture content. These other factors were regarded as minor because they do not affect the relationship between the Resource and Reserve. For example, the average moisture content was estimated to be approximately $2.5 \%$ for all seams. Total moisture content is known to have an effect on coal recovery. The study was limited to losses and dilution; these are the two factors that contribute the most in the Reserve model, and can be estimated based on experience or benchmarks, and measured. These two factors can be measured through survey reports and from plant belt weightometer measurements, but both methods are open to errors. In principle, the Reserve tonnages should be consistently more or less than the Resource tonnages. An increase in the dilution factor resulted in an increase of Reserve tonnages, while losses decreased the Reserve tonnages.

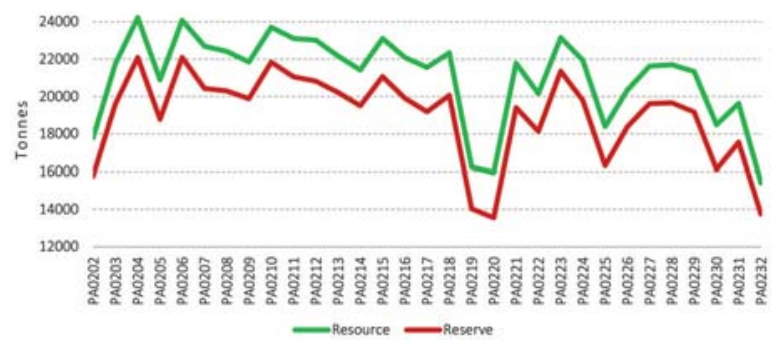

Figure 5-Resource and Reserve utilization mass balance - S4L PA02

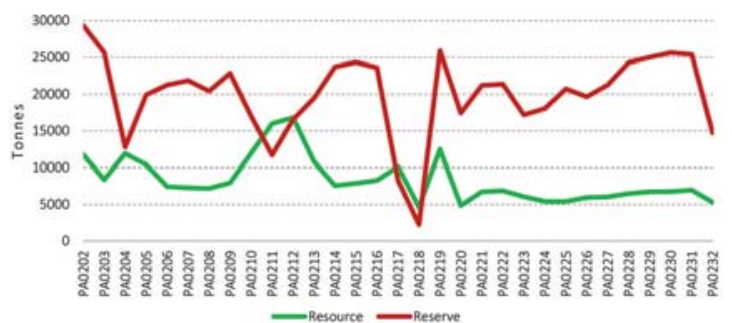

Figure 6-Resource and Reserve utilization mass balance - S2P PA02

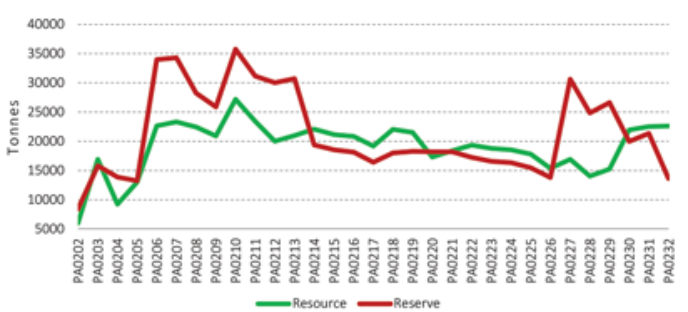

Figure 7-Resource and Reserve utilization mass balance - S1 PA02

\section{Table II}

Assumptions used in converting Resources to Reserves

\begin{tabular}{|c|c|c|c|c|c|c|c|c|c|}
\hline \multicolumn{5}{|c|}{ Losses (\%) } & \multicolumn{5}{|c|}{ Dilution (\%) } \\
\hline Seam & Roof & Floor & Edge & Other & Roof & Floor & Edge & Bord collapse & Other \\
\hline $\begin{array}{l}\text { S4L } \\
\text { S2RP } \\
\text { S1 }\end{array}$ & $\begin{array}{l}5 \\
2 \\
5\end{array}$ & $\begin{array}{l}5 \\
0 \\
5\end{array}$ & $\begin{array}{l}0 \\
2 \\
2\end{array}$ & $\begin{array}{l}7 \\
5 \\
7\end{array}$ & $\begin{array}{l}5 \\
2 \\
5\end{array}$ & $\begin{array}{l}5 \\
0 \\
5\end{array}$ & $\begin{array}{l}0 \\
2 \\
2\end{array}$ & $\begin{array}{c}0 \\
20 \\
0\end{array}$ & $\begin{array}{l}7 \\
5 \\
7\end{array}$ \\
\hline
\end{tabular}




\section{Factors and challenges affecting coal recovery by opencast pillar mining in Witbank}

However, the dilution factor has to be kept within allowable levels. If the dilution is too high the following ensues:

> Tonnages to be mined and processed increase, hence operating costs increase

$>$ Quality of coal decreases

> Time of operating increases.

\section{Dilution during opencast pillar mining}

In general, dilution is defined as the percentage of non-coal material that is unintentionally blasted and loaded together with coal and delivered to the plant. The selected mining method uses a blasting technique called bord collapse, which intentionally allows the occurrence of high dilution by collapsing the bords. One of the main reasons for collapsing the bords is to maximize coal recovery. Baruya (2012) explained that dilution affects the quality of coal in the mining process. Reserve models take into account the amount of dilution that is expected during mining activities.

The quantification of dilution requires that waste handling is controlled and reduced by understanding its root causes. The factors that affect dilution are as follows according to Ebrahimi (2013):

- Characteristics of the deposit

- Method and scale of operation

> Types and size of equipment

> Operator skills and overall mine geometry.

It is necessary to quantify dilution in order to improve the design of a mine and evaluate project economics (Ebrahimi, 2013). According to the Reserve model, that there will be $5 \%$ roof and floor dilution for the virgin coal seams and $20 \%$ for the S2RP seam due to the bords. The high dilution in the S2RP seam is a result of the waste material that falls into and fills up the bords after blasting the midburden.

Figure 8 shows the variation in dilution in a pillar mining operation. It should, however, be noted that this data is for a blend of the three seams. The run of mine (ROM) volumes entering the plant are divided into three products, namely fines material, which is sent to slimes dams; reject material, which includes coal material that is below the cut-off grade; and product, which is the tonnages on the weightometer. The variation in data between the pit and plant has been attributed to the manner in which dilution is measured and calculated.

Figure 8 represents the percentage of discard material rejected by the processing plant from monthly ROM tonnages. The majority of the dilution material is expected to be generated from collapsing the bords in the S2RP, while the rest is expected from the top of the seam, bottom of the seam, and edge of the seams during operations in the Reserve model. However, it was noted that the data from the plant may include a blend of the three seams, losses from fines going into slimes dams, reject coal, and coal below quality cut-off. The dilution of the S1 and S4L seams was relatively easy to estimate, while the S2RP seam dilution could not be easily defined. The following factors and assumptions were taken into consideration in theoretically determining the dilution factor for the S2RP seam:

> The pillars remain intact after blasting the midburden

> The roof coal above the bords is semi-collapsed after blasting the midburden and falls directly into the voids (see Figure 9)
> Scaling of the pillars remains unchanged or the fallouts accumulate on the floor with the tonnages remaining the same

> The blasted material increases in volume by $60 \%$.

Measuring and estimating dilution can be attributed by a variation in data. Determining the exact amount of dilution would require continuous measuring from the plant data, pit data, as well as over an extensive area.

The blasted midburden is allowed to fall above the pillars and thus fractures the roof coal, which is approximately $1.0 \mathrm{~m}$ thick. The midburden is drilled to the top of the roof coal to limit the air entering the old workings. It was initially predicted that the roof coal would fully collapse directly into the voids, while the pillars remained intact. It was then noticed that the roof coal is actually semi-collapsed by the midburden material after blasting. This can be seen in Figure 9, which illustrates the two collapse scenarios for the roof coal.

The ideal scenario depicts the manner in which the roof coal and pillars were expected to collapse. It was assumed that the blasting of the midburden would fully collapse the roof coal above the bords, allowing it to fall directly in the bord void. In this scenario the roof coal above the bord is pushed to the floor and is fractured. The bord voids are completely filled with midburden material.

The actual scenario depicts the situation whereby the roof coal above the bords is semi-collapsed as the midburden is blasted, leaving some unfilled voids. The roof coal becomes mixed with the blasted material during the collapse. The bords are always collapsed, but in some cases the roof coal in the bords may not be fully or perfectly collapsed. This situation remains unchanged even when the draglines works above the pillars. The voids caused by the semi-collapse of the roof coal allow air to penetrate the underground workings, resulting in spontaneous combustion.

$$
\text { Dilution }=\frac{\text { Waste material (Tons) }}{\text { Total ROM material (Tons) }}
$$

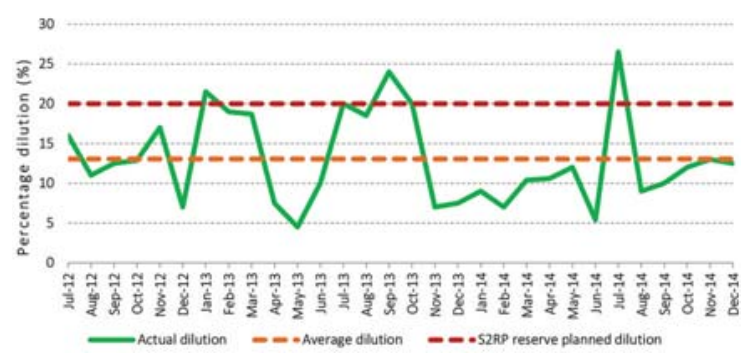

Figure 8-Dilution factor according to the processing plant

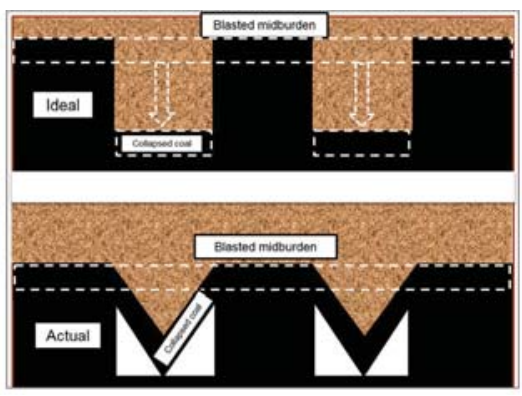

Figure 9-Roof coal collapse scenarios 


\section{Factors and challenges affecting coal recovery by opencast pillar mining in Witbank}

The actual dilution in the S2RP seam is approximately $21.0 \%$, which is $1.0 \%$ higher than estimated in the Reserve model. The main aim of building the Reserve model was to estimate conditions after blasting, exposure, and extraction. The dilution decreases to $19 \%$ in areas surrounded by barrier pillars. The amount of dilution in the actual scenario is reduced because of the unfilled voids. Dilution increases the ROM coal quantity while effectively reducing the calorific value and quality of the coal (Baruya, 2012). Mines will tend to increase dilution and encounter greater challenges of dilution when seeking to maximize coal recovery from the coal Reserve. This does not apply in cases where the plant is used to remove contamination, but only in cases where the coal is not beneficiated.

\section{Coal losses and reconciliation}

Mining operations expend huge sums in capital and operating costs for the extraction of resources. Several processes are carried out before coal extraction begins. A Reserve model is built to accommodate any potential losses and dilution during extraction.

Figure 10 shows the variance between the tonnages of coal in Reserves, which are converted from the theoretical Resources, and the actual amount of coal exposed and recovered per mining block as measured by the surveyor. This data was obtained over various individual mining blocks for which survey reports had indicated significant losses.

Figure 10 shows that a significant amount of coal was not recovered during the mining processes. In principle, the amount of coal recovered (actually mined) and the Reserve coal should be roughly the same. This is because the Reserve model is constructed to accommodate these potential Resource losses and dilution. These variances indicate that some valuable coal is lost during the extraction process. Field investigations were carried out to determine the types of coal losses that occur in the pit. The types of losses and average tonnage loss per mining block for the three seams are shown in Figure 12. A proposed coal process flow model that shows the stages through which the coal proceeds is shown in Figure 11.

Figure 11 illustrates the random occurrence of different types of coal losses in individual mining blocks for the three seams. The diagram shows the worst cases of recorded coal losses that were encountered in certain individual and random mining blocks. The losses were found to have very low occurrence rates.

Geological and geotechnical losses occur naturally and randomly across all seams and cannot be physically prevented. The geological losses are dominant on the S1 seam due to mining blocks being partially mined or left unmined as a result of the parting being above cut-off thickness. The parting material is situated above the $\mathrm{S} 1$ seam and makes it difficult or uneconomical to extract the seam in certain blocks.

Highwall losses occur as a result of underbreak on the highwall. There is potential for recovering these losses on the next strip if the exposure is dedicated and prepared for the recovery as buffer blasting is also in place. However, there are risks involved in doing so because this can result in greater losses and damage. The Reserve model does not take highwall losses on the S4 into account because of the implementation of pre-split blasting on the upper 4 seam bench. These losses are higher on the S2RP and S1 than the
S4L because the midburden is not pre-split blasted. The rock properties have an influence on the effectiveness of pre-split blasting. Pre-split blasting is better suited for hard material than for oxidized or weathered overburden material.

Figure 13 illustrates the occurrence of highwall losses. Highwall blasting with respect to pre-split blasting should be reviewed and monitored frequently in order to reduce highwall losses. The implementation of accurate pre-split blasting procedures is the key to the minimization of highwall losses. The pre-split is blasted only on the overburden (S4L seam), and not on the midburden which sits above the pillars.

Edge of seam/low-wall losses occur due to a collapse of the spoil. The spoil material begins to roll down and starts covering the edge of the seam on the low-wall side. This is due to increased volume of stripped material. Edge losses increase with depth from the S4L to the S1, thus S4L edge losses $<<$ S2RP edge losses $<$ S1 edge losses. This results from the increase in the volume of the stripped material. This is noted in the vicinity of ramps or corners in the pit where there is limited space for spoil material.

Attempts to recover edge of seam losses are strictly prohibited due to the risks associated with disturbing spoil, which can collapse, resulting in increased edge of seam losses. Correct parameters, such as the amount of material to

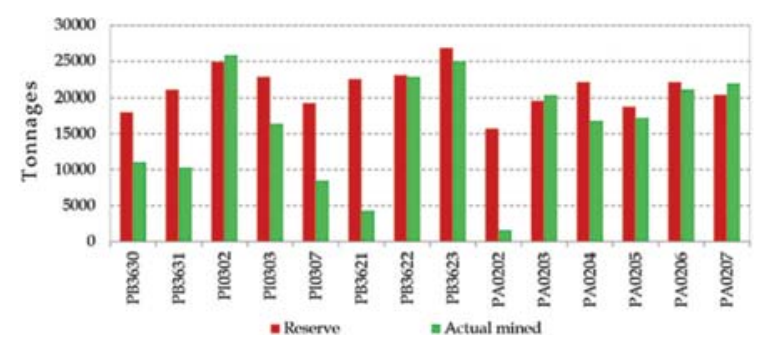

Figure 10-Random and individual mining blocks affected by losses and dilution

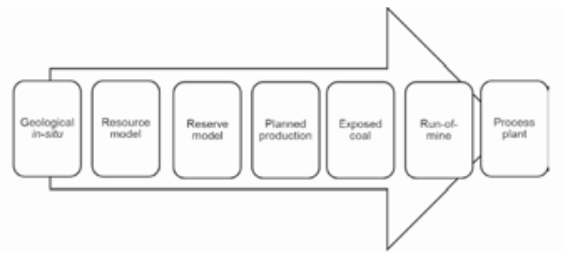

Figure 11-Coal flow process model

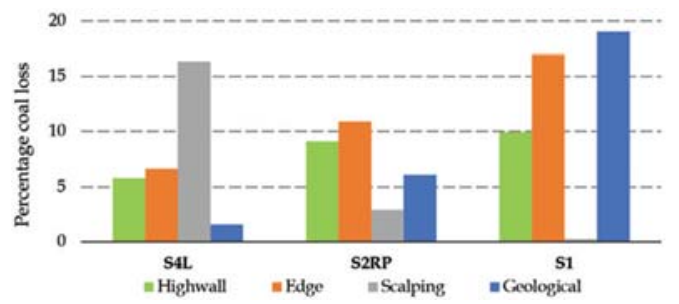

Figure 12-Coal losses for individual mining blocks in the three seams

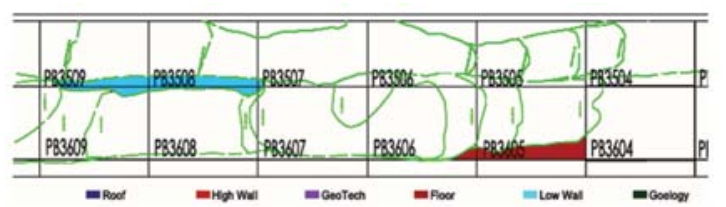

Figure 13-Highwall losses (red shading) 


\section{Factors and challenges affecting coal recovery by opencast pillar mining in Witbank}

be exposed, positioning of draglines (total distance of reach of dragline), and positions of access ramps can prevent edge of seam coal losses. Another method is to create a $5.0 \mathrm{~m}$ wide void at the edge of the seam as a safety measure for occasionally collapsing spoil. The void can alternatively be used in areas where there are high volumes of material to be exposed. For localities with limited spoil area, such as ramps, the void can be deepened where necessary. A review on the pre-stripping of the overburden can be conducted to reduce and eliminate the occurrence of edge of seam coal losses.

Scalping or top of coal seam losses. The dragline bucket starts scalping the top of the coal seam during exposure, which results in losses. This can be quite significant during the night shift as the visibility of the interface between waste material and coal is affected. The hardness of the coal determines the rate of this loss. The S4L seam is generally softer, hence is subject to higher scalping losses, whereas the hardness of the S2RP and S1 prevents large scalping losses. The scalping losses in this case decrease with depth, thus S4L scalping losses $>>$ S2RP scalping losses $>>$ S1 scalping losses.

The top of coal losses are indicated by the purples lines in Figure 15, where green represents some geological losses. Top of coal losses during exposure can be effectively managed through careful dragline operation. With the functional capabilities of draglines and the known depths of the seams, a digging limit with reference to the seam depth should be implemented on the draglines to prevent scalping. The S4L is still virgin coal and thus scalping losses in pillar mining and conventional mining should not be different.

Floor losses result when coal is left on the floor. Floor losses were found to be minimal across all seams. Credit can also be given to the efficiency of operators in the extraction crew. The occurrence of floor losses depends on the ability of the loader or excavator bucket to penetrate the bottom of the seam. Water accumulation affects the visibility of the bottom of the seam, and the loader operator may struggle to see coal remaining on floor. However, floor losses are often marginal.

Figure 16 displays a sectional view summarizing the different coal losses as described above.

Preventative strategies need to be implemented in order to minimize coal losses. These could include non-technical strategies, which influence the overall productivity of workers. Operators are working directly with the coal in the pit and can play a major role in the prevention of coal losses. Operators should be familiarized with the effects of coal losses and dilution. Refresher courses where operators are taught about the influences of coal losses in the mining business can be implemented. The courses should also be aimed at training operators, such as dragline and loaders operators, to distinguish the types of material by colour, hardness, or other properties.

The stages that the coal goes through (from in situ to the plant) are illustrated in the proposed coal recovery model in Figure 17. The factors associated with each stage or processes are also highlighted. Some coal losses occur through blast damage to the coal seams, when the coal becomes locked up with the overburden material during the blast. Guidelines for the drilling and blasting cycle should be provided, and compliance with working procedures should be well supervised. The workers and operators should be acquainted with the relevant working procedures. For example, the blasting crew should understand the reasons for backfilling over-drilled blast-holes, and the drill operators should understand the reasons for re-drilling an underdrilled blast-hole.

Scott and Wedmaier (1995) investigated the sources of coal losses and dilution. Coal losses have a direct relationship to dilution. It was concluded that the roof of the seam experiences more losses than dilution, while there is more dilution than losses at the bottom of the seam (Baruya, 2012). The following were identified by Baruya (2012) as the major factors influencing the occurrence of coal damage, losses, and dilution:

> Blast damage: during blasting operations of the overburden, mid-burden, and parting material at the top of the coal seam

> Type of equipment used (draglines versus truck and shovel) for coal exposure

> Extraction method and equipment: loader and truck extraction method and size of the equipment

- Equipment movement on top of coal

$>$ Geometry of the top of coal and floor conditions: the deposition of the coal seams relative to the horizontality of the surface

> Coal properties: hardness and colour of the coal seam

> Operator experience and visibility

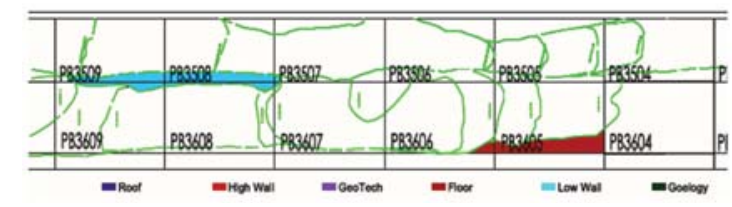

Figure 14-Edge of seam losses (blue shading)

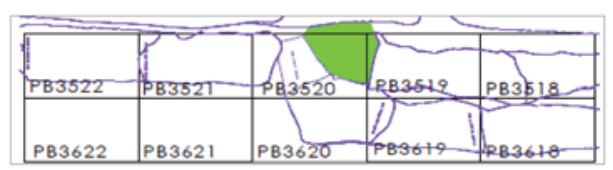

Figure 15-Scalping losses

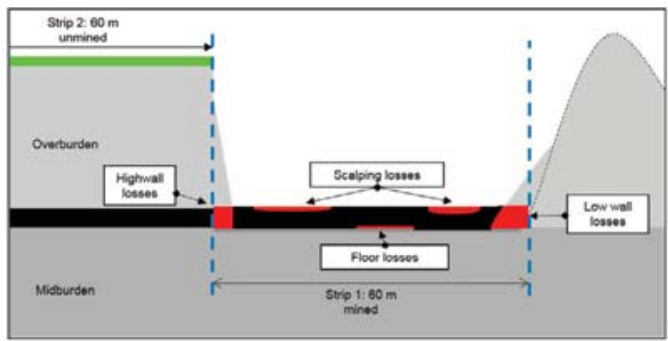

Figure 16-Sectional view illustrating the different coal losses

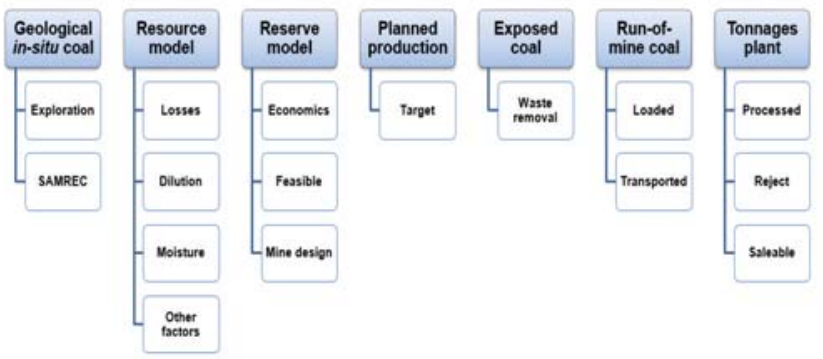

Figure 17-Coal recovery model - flow of coal 


\section{Factors and challenges affecting coal recovery by opencast pillar mining in Witbank}

> Presence of water in the coal exposure and loading activities.

\section{Effects of spontaneous combustion}

Opencast pillar mining can be widely affected by spontaneous combustion. Spontaneous combustion in coal mines is simply the oxidation of self-heated coal, resulting in burning of in situ coal (Eroglu and Moolman, 2003; Phillips et al., 2011). Spontaneous combustion affects the calorific value of coal, leads to the emission of noxious gases, and contributes to coal losses both directly and indirectly. The direct losses occur as coal continues to burn in the ground, and the value and quantity of the coal is decreased. The indirect losses are a result of the effect of burning coal on productivity.due to:

> Relatively complex hot-hole blasting procedures

- Excessive dust generation during exposure activities, which affects visibility during dragline operations

> Delays (such as treating hot holes and extinguishing open fires) due to spontaneous combustion that affect productivity and operating costs

- Reduced stockpiling as burning coal is sent directly to the plant

- Risk of people and machines working close to burning areas.

The basic principle in controlling and preventing spontaneous combustion is to eliminate one of the requisite components - fuel, heat, and oxygen. Fuel (coal in this case) and heat from underground self-heating cannot be eliminated in practice. While there are various ways in which oxygen can ingress the underground self-heated coal, oxygen seems to be the key issue in dealing with spontaneous combustion (Eroglu and Moolman, 2003). Spontaneous combustion will further contribute to coal losses if air continuously penetrates the old workings. The quality and quantity of coal is affected by spontaneous combustion. Spontaneous combustion necessitates the need for specialized techniques such as hothole blasting, buffering, and cladding. Excessive dust is encountered during dragline exposure activities as a result of burning coal and this affects the productivity of the operation as a whole. The presence of dust increases dragline cycle times, hence lowering productivity.

The occurrence of spontaneous combustion can be effectively prevented and well managed through the use of a buffer and cladding blasting. These two techniques were initially used separately, but there were still signs of spontaneous combustion. It was then decided to combine the two techniques for the same purpose, as shown in Figure 18.

The cladding technique is used to minimize the entry of oxygen into the bord areas. The blasted muck-pile covers the no. 2 seam pillar coal with oxidized overburden material. A dozer may be used to push over more material to make sure that the area is sealed off completely. The buffer management technique ensures that the voids are completely filled with non-combustible material to limit entry of oxygen into the bord voids. These techniques have proven to be successful in the elimination and prevention of spontaneous combustion, and have the following benefits:

> Reduction of direct coal losses

- Improved productivity

- Reduced hot areas and hence a minimization of the use of hot-hole blasting procedures

$>$ Control of the risks to people and equipment associated with loading of burning coal

> Healthier and safer working conditions.

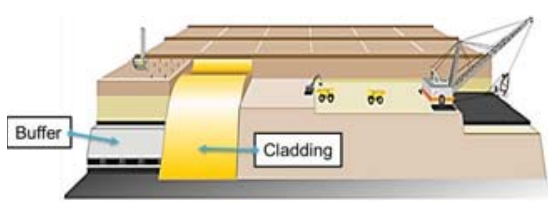

Figure 18-Typical cladding and buffer management techniques

\section{Conclusion}

Opencast pillar mining is fairly similar to conventional opencast mining in principle; however, it entails various unique challenges. Opencast pillar mining is faced with the risks of spontaneous combustion, coal losses, high dilution due to the bords, imperfectly known conditions, and inaccurate plans of the old workings. Mining of old pillars is, however, viable due to the good quality coal in the pillars. The consequences of dilution and coal loss in pillar mining methods are more severe than in conventional opencast mining. This paper has shown that coal recovery can be improved if the process plant is capable of handling large amounts of dilution material. If this is not the case, the operation should attempt to mine accurately to avoid dilution, but this may result in coal losses. The flow of the coal process was investigated from in situ geological tonnages up to the point that the coal reaches the process plant. This procedure indicated errors and inaccuracies in the data measuring practices. Various types of coal losses were investigated, and certain types of losses were found to be influenced by the mining of old pillars, such as coal lost due to spontaneous combustion and flooding of the old workings. The impact of the factors and challenges of opencast pillar mining on coal recovery can be managed to prevent adverse effects on productivity, minimize coal losses, and control dilution.

\section{References}

BARUYA, P. 2012. Losses in the coal supply chain. IEA Clean Coal Centre, London, UK.

EBRAнimi, A. 2013. The importance of dilution factor for open pit mining projects. Proceedings of the 23rd World Mining Congress, Montreal. CIM, Montreal.

Eroglu, N. and Moolman, C. 2003. Development methods to prevent and control spontaneous combustion associated with mining and subsidence. Coaltech 2020. Division of Mining Technology, CSIR.

INFoMINE. 2015. http://www.infomine.com/investment/metal-prices/coal/all/

JEFFREY, L.S. 2002. Geotechnical factors associated with previously mined areas of coal and their impact on subsequent extraction. MSc thesis, University of the Witwatersrand.

Johnston, S.N. and KeLLEHER, M.L. 2005. Keep the cream - reconciling coal recovery at BMA Goonyella Riverside. Proceedings of Coal 2005: Coal operators' Conference. Aziz, N. (ed.). University of Wollongong and the Australasian Institute of Mining and Metallurgy. pp. 161-168.

Mine X Colliery. 2015. Survey plans, Resource and Reserve models, Process plant data, and Internal reports and presentations.

Mine X COLLIERY PERSONNEL. 2015. Personal communications.

Phillips, H., Uludag, S., and Chabedi, K. 2003. Prevention and control of spontaneous combustion. Best practice guidelines for surface coal mines in South Africa. Coaltech 2020. Division of Mining Technology, CSIR.

SAMREC. 2009. South African Mineral Resource Committee. The South African Code for Reporting of Exploration Results, Mineral Resources and Mineral Reserves (the SAMREC Code). 2007 Edition as amended July 2009. http://www.samcode.co.za/downloads/SAMREC2009.pdf

ScHALEKAMP, E.E. 2006. The financial viability of coal reserves within previously mined areas of the Witbank coalfield. Masters thesis, University of Pretoria.

ScotT, A. and Wedmaier, R. 1995. The assessment and control of coal damage and loss. Final report C3017. Australian Coal Association Research Program (ACARP), Brisbane, Australia. 93 pp.

Thompson, R.J. 2005. Surface Strip Coal Mining Handbook. South African Colliery Mine Managers Association. 